\title{
Effect of purity on the vacancy defects induced in self- irradiated tungsten: a combination of PAS and TEM
}

\author{
Z. Hu' ${ }^{1}$, P. Desgardin ${ }^{1}$, C. Genevois ${ }^{1}$, J. Joseph ${ }^{1}$, B. Décamps ${ }^{2}$, R. Schäublin ${ }^{3}$, M-F. Barthe ${ }^{*, 1}$ \\ ${ }^{1}$ CEMHTI, CNRS, UPR3079, Univ. Orléans, F-45071 Orléans, France \\ ${ }^{2}$ IJCLab/CNRS, Paris - Saclay University, France \\ ${ }^{3}$ Laboratory of Metal Physics and Technology, Dept. of Materials, ETH Zurich, Switzerland \\ Keywords: Tungsten, self-irradiation, light-element impurities, vacancy-complexes, Positron \\ annihilation spectroscopy, TEM
}

\section{Abstract:}

Vacancy defects in tungsten induced by self-irradiation were characterized by positron annihilation spectroscopy (PAS) and transmission electron microscopy (TEM). Taking advantage of their complementarity, defects ranging from single vacancies up to vacancy clusters were detected, and the effects of sample purity (99.95 wt.\% and 99.9999 wt.\%) on their formation and evolution under low damage dose ( 0.01 to $0.02 \mathrm{dpa}$ ) irradiation with 20 and $1.2 \mathrm{MeV}-\mathrm{W}$ ions were studied at room temperature (RT), 500 and $700{ }^{\circ} \mathrm{C}$ respectively. When irradiation was performed at RT, PAS probed mainly single vacancies. At high irradiation temperatures, larger vacancy clusters were detected by both techniques. Both PAS and TEM revealed larger vacancy clusters in the purest samples after irradiation at 500 and $700{ }^{\circ} \mathrm{C}$. A significant difference in the evolution of vacancy-type defects related to sample purity was observed. In view of the properties (migration, trapping) of some light-element impurities (LEs), present at high concentrations, determined by first-principles calculation, it is reasonable to assign the effect of purity during the irradiation response to the formation of vacancyimpurity complexes, which is critical for the understanding of the behavior of tungsten in the future fusion reactor.

\section{Introduction}

Tungsten, the basic material for several components facing the thermonuclear fusion plasma in the ITER (International Thermonuclear Experimental Reactor) experimental tokamak, in particular for the 
divertor [1,2], is also envisaged to cover the first wall of DEMO (DEMOnstration Power Plant) [3]. Its high melting point, efficient thermal conductivity, and low sputtering yield are advantageous for the secure operation of future fusion reactors in which materials will be subjected to extreme conditions. Tungsten will have to undergo high heat fluxes and the impact of hydrogen isotopes and helium (respectively the plasma fuel and the fusion reaction product). According to theoretical and experimental work, these severe conditions induce the formation of bubbles [4] leading to a fuzzy [5] and blistering surface [6] as well-known consequences of helium and hydrogen introduction, respectively. Simultaneously, high-energy particles (14.1 MeV neutrons and 3.5 $\mathrm{MeV} \alpha$ ) bombard the plasma-facing walls, creating various defects whose evolution is probably accelerated by the high temperature, and giving rise to drastic modifications in the tungsten microstructure. Irradiationinduced defects such as dislocation loops $[7,8]$ and vacancy-type defects $[9,10]$ have been experimentally observed in tungsten using either TEM or PAS. Only a few studies report analysis of neutron irradiated tungsten using PAS [11-14]. Furthermore, a large number of studies [15-17] have demonstrated that the transmutation elements (TEs) interact strongly with the aforementioned irradiation-induced defects. Their precipitation results in further degradation of mechanical properties [18-20]. As all these irradiation-induced defects negatively affect the performance and reliability of future reactors, it is critical to understand their nature, formation and evolution mechanisms to better predict them and potentially mitigate them.

Recently, Castin et al. [21] demonstrated the influence of carbon on the formation of loops by using object kinetic Monte Carlo (OKMC) modeling and secondary ion mass spectroscopy (SIMS). Besides, first-principle calculations predicted that vacancy-type defects interact strongly with LEs. Table 1 sums up the results of first-principles calculations of the $L E(H, C, N, O)$ properties [22-30], indicating that LE $(\mathrm{H}, \mathrm{C}, \mathrm{N}, \mathrm{O})$ are apt to locate at octahedral or tetrahedral interstitial sites in the vicinity of single vacancies in the tungsten matrix. By comparing the migration energy of the single vacancies $\left(E_{m}^{V_{1}}=\right.$ $1.66 \mathrm{eV}[31])$, the lower migration energies $E_{m}^{X_{1}}$ of single LE atoms indicates their higher mobility in the tungsten matrix than that of single vacancies. In addition, the strong binding energies between LE 
atoms and single vacancies indicate that LEs tend to be trapped at single vacancies. It is possible to trap more than one LE atom in a single vacancy. For instance, a single vacancy can trap as many as 12 hydrogen atoms [22], 4 carbon atoms [23], 6 nitrogen atoms [24], and 6 oxygen atoms [25]. However, except for these theoretical results, it is difficult to find an experimental study concerning LE-vacancy complexes and their impact on the evolution of the microstructure of tungsten under irradiation. In a similar study on carbon-doped bcc iron, Vehanen et al. [32] demonstrated the practicability of positron annihilation spectroscopy and showed that carbon-vacancy complexes are formed in stage III (200 K, related to $\mathrm{V}$ migration) due to the trapping of vacancies by carbon atoms, impeding the clustering of vacancies up to about $450 \mathrm{~K}$ when dissociation of the V-C complex was observed. They also showed that at about $350 \mathrm{~K}$ carbon atoms become mobile, and can be trapped at $\mathrm{V}-\mathrm{C}$ complexes. The greater the number of carbon atoms $n$, the more the $V-C_{n}$ complexes generated hinder the trapping of positrons.

\begin{tabular}{|c|c|c|c|c|}
\hline$x$ & $\begin{array}{l}E_{f}^{X} \\
(e V)\end{array}$ & $\begin{array}{l}E_{m}^{X} \\
(e V)\end{array}$ & $\begin{array}{c}E_{b}^{V_{1}-X_{1}} \\
(e V)\end{array}$ & $\begin{array}{c}E_{b}^{V_{1}-X_{n}} \\
(e V)\end{array}$ \\
\hline & 4.05 (SS) & 0.21 (TIS-TIS) [27] & $1.24[28]$ & $0.20[22]$ \\
\hline$H$ & $\begin{array}{l}0.93 \text { (TIS) [26] } \\
1.27 \text { (OIS) }\end{array}$ & 0.59 (OIS-TIS) & & $\left(\mathrm{V}_{1}-\mathrm{H}_{12}\right)$ \\
\hline & 4.25 (SS) & 1.46 (TIS-OIS) [23] & $1.93[23]$ & 0.55 [23] \\
\hline$c$ & $\begin{array}{l}2.24-2.28 \text { (TIS) [28] } \\
0.78 \text { (OIS) }\end{array}$ & 3.87 (OIS-TIS) & & $\left(V_{1}-C_{4}\right)$ \\
\hline$N$ & $\begin{array}{l}-0.13 \text { (SS) } \\
-3.06 \text { (TIS) [29] } \\
-3.79 \text { (OIS) }\end{array}$ & $\begin{array}{l}0.73 \text { (TIS-OIS) [29] } \\
3.60 \text { (OIS-TIS) }\end{array}$ & $2.48[24]$ & $\begin{array}{l}9.66[24] \\
\left(\mathrm{V}_{1}-\mathrm{N}_{6}\right)\end{array}$ \\
\hline 0 & $\begin{array}{l}0.5 \text { (SS) } \\
-1.75 \text { (TIS) [25] } \\
-1.43 \text { (OIS) }\end{array}$ & $\begin{array}{l}0.17 \text { (TIS-TIS)[25] } \\
0.32 \text { (TIS-OIS) }\end{array}$ & $3.05[25]$ & $\begin{array}{c}11.21[24] \\
\left(\mathrm{V}_{1}-\mathrm{O}_{6}\right)\end{array}$ \\
\hline
\end{tabular}

\section{Table 1: Calculated formation energy $E_{f}^{X}$, migration energy $E_{m}^{X}$ of element $X$ and its binding energy with a} tungsten single vacancy $E_{b}^{V_{1}-X_{1}}$, and the binding energy, $E_{b}^{V_{1}-X_{n}}$ of a tungsten single vacancy with the maximum of LE atoms that can be trapped, $n$. (SS: substitutional site TIS: tetrahedral interstitial site, OIS: octahedral interstitial site) [19-27].

In this paper, we show the first experimental results elucidating the impact of LE-vacancy interactions on the vacancy's evolution in irradiated tungsten. We introduced vacancy-type defects into tungsten samples of two purity levels i.e. 3N-HP (99.95 wt.\%) and 6N-XHP (99.9999 wt.\%) by self-irradiation of 
20 and $1.2 \mathrm{MeV}$ at various temperatures $\left(\mathrm{RT}, 500^{\circ} \mathrm{C}\right.$, and $\left.700{ }^{\circ} \mathrm{C}\right)$. Post-irradiation characterizations were performed by TEM to directly observe the cavities with sizes above $\sim 0.5 \mathrm{~nm}$. To characterize the vacancy-type defects below the TEM detection limit, we employed PAS as it enables the probing of vacancy-type defects from single vacancies to vacancy clusters made of up to around 30 vacancies.

\section{Experimental details}

\subsection{Sample preparation and irradiation conditions}

This experimental study was carried out in polycrystalline W samples with two purity levels. The lower purity samples were laminated high purity (HP) samples (99.95 wt.\%, 3N-HP, H: $<910$ ppm C: $<460$ ppm $\mathrm{N}:<130 \mathrm{ppm}$ 0: $<345 \mathrm{ppm}$ ) purchased from Goodfellow. The extra-high purity samples (XHP) were provided by Forschungszentrum Jülich (99.9999 wt.\%, 6N-XHP, H, C, O, and N undetectable by LA-ICPMS (Laser Ablation Inductively Coupled Plasma Mass Spectrometry)). Two shapes of samples, adapted to the characterization technique, were used: $7 \times 7 \mathrm{~mm}^{2}$ squares for PAS and $\varnothing 3 \mathrm{~mm}$ discs for TEM. They were first polished using abrasive SiC papers (P600 to P2500) and then the surface was improved by flocked felt (FD3 to FD1) from the ESCIL company. Next, the single-face mirror-polished samples were rinsed in an ultrasonic bath for 20 minutes in acetone and then in ethanol. Then, as-polished samples were annealed in a high vacuum $\left(<10^{-7} \mathrm{mbar}\right)$ furnace at $1700^{\circ} \mathrm{C}$ for 3 hours to eliminate the native and polishing-induced defects. The grain sizes after annealing were evaluated by light microscopy (Figure 1). The mean size was about $500 \mu \mathrm{m}$ and $200 \mu \mathrm{m}$ for the $3 \mathrm{~N}-\mathrm{HP}$ sample and $6 \mathrm{~N}$ XHP sample, respectively. The as-annealed discs $(\varnothing 3 \mathrm{~mm})$ prepared for TEM observations were electropolished into thin foils (electron transparent areas of $\sim 60 \mathrm{~nm}$ thickness) using Tenupol-5 with a double jet of prepared $\mathrm{NaOH}$ solution $\left(0.05 \mathrm{~mol} / \mathrm{L}, 15^{\circ} \mathrm{C}\right.$, and $\left.15 \mathrm{~V}\right)$ for 10 minutes. Lastly, the thick square samples (thickness $>100 \mu \mathrm{m}$ ) were checked prior to irradiation by PAS for further comparison, and the thin foil samples were qualified by TEM. The qualified thin foil samples have homogenous large grains with the lowest possible dislocation density and other microstructural defects. 

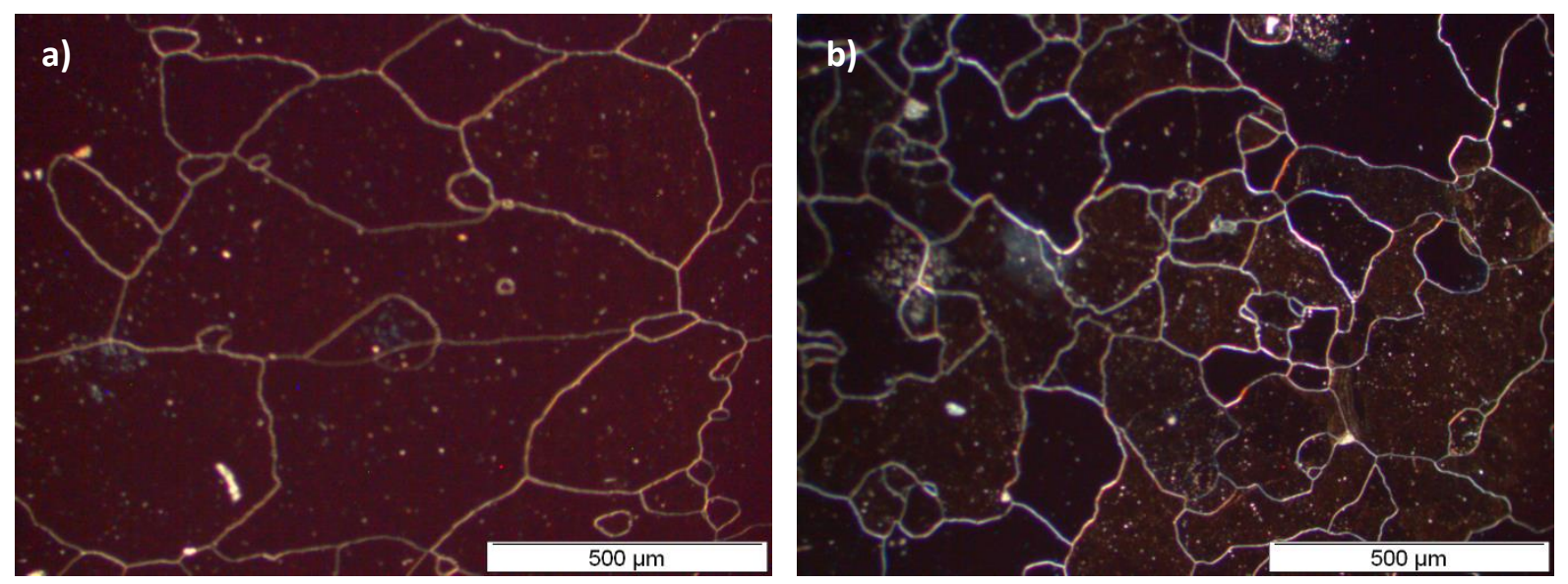

Figure 1: Well-annealed polycrystalline tungsten samples a) 3N-HP 99.99 wt.\% and b) 6N-XHP 99.9999 wt.\%

Self-irradiation was performed at various temperatures RT, 500 , and $700{ }^{\circ} \mathrm{C}$, and the energy of the tungsten ions was adapted to the depth of the region that could be probed by TEM and PAS. The thick square samples were ex-situ irradiated by $20 \mathrm{MeV}-\mathrm{W}^{+}$and the thin foils were in situ damaged with 1.2

$\mathrm{MeV}-\mathrm{W}^{+}$in the electronic transmission microscope at the JANNuS (Joint Accelerators for Nano-science and Nuclear Simulation) platform [33]. The ion beam incidence was fixed at $15^{\circ}$ for the most energetic ions and $45^{\circ}$ for in situ irradiations. The profiles of induced damage dose versus depth were estimated using the quick calculation option based on Kinchin-Pease formalism in the SRIM-2008 (The Stopping and Range of lons in Matter) program. The value of the displacement energy threshold $E_{d}$ was fixed at $55.3 \mathrm{eV}$ as recommended by Dudarev [34] and the lattice binding energy $\mathrm{E}_{\mathrm{b}}$ was $0 \mathrm{eV}[35]$. As shown in Figure 2, for pertinent fluences $\left(7.48 \times 10^{12} \mathrm{~cm}^{-2}\right.$ for $20 \mathrm{MeV}-\mathrm{W}^{+}$in thick samples and $1.8 \times 10^{12} \mathrm{~cm}^{-2}$ for 1.2 MeV- $\mathrm{W}^{+}$in lamella samples), the mean damage dose in the characterized region (the first $700 \mathrm{~nm}$ and $50 \mathrm{~nm}$ for PAS and TEM, respectively) was equivalent for both energy irradiations, around 0.02 dpa. The experimental fluxes were fixed at $2.8 \times 10^{10} \mathrm{~cm}^{-2} \cdot \mathrm{s}^{-1}$ and $3.3 \times 10^{9} \mathrm{~cm}^{-2} \cdot \mathrm{s}^{-1}$, respectively, in order to obtain a comparable mean damage rate of about $5 \times 10^{-5} \mathrm{dpa} . \mathrm{s}^{-1}$. 

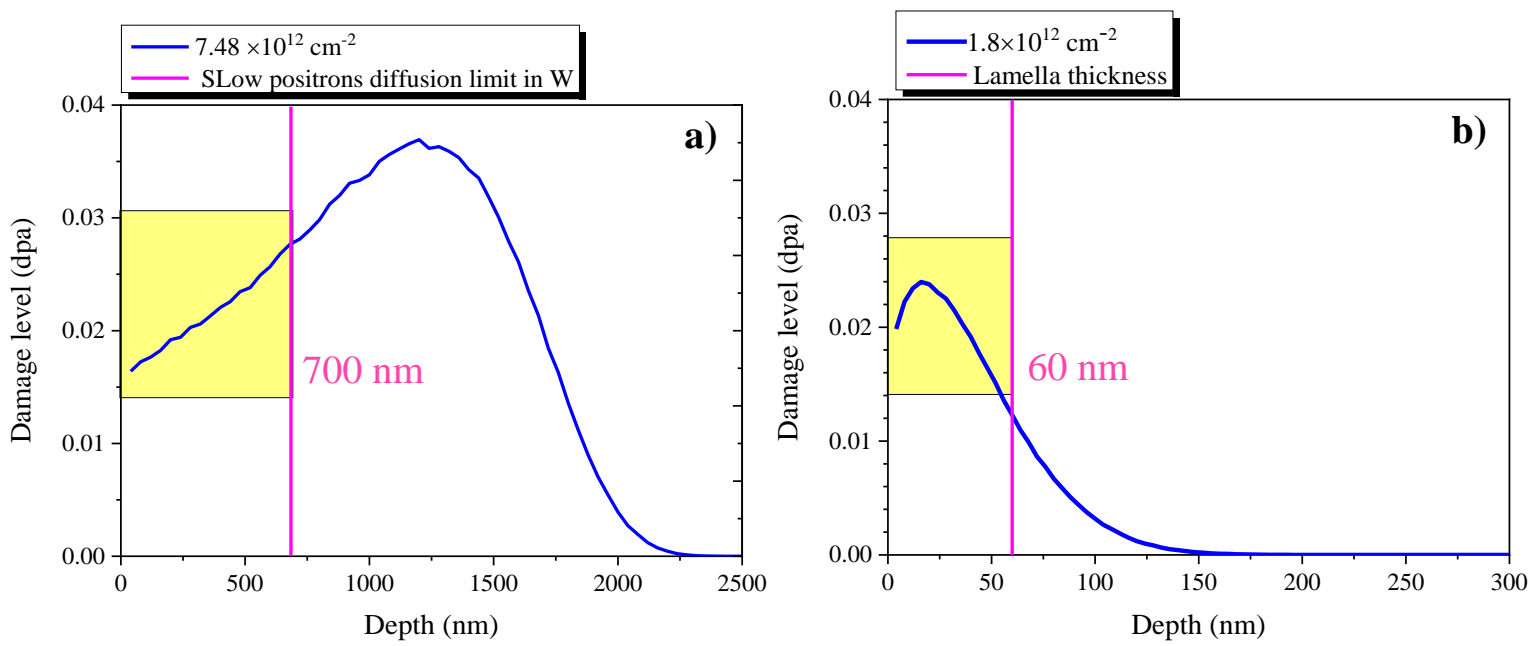

113

Figure 2 : a) Damage profile of self-irradiation with $7.48 \times 10^{12} \mathrm{~W}^{+} . \mathrm{cm}^{-2}\left(15^{\circ}, 20 \mathrm{MeV}\right)$, b) damage profile of selfirradiation with $1.8 \times 10^{12} \mathrm{~W}^{+} . \mathrm{cm}^{-2}\left(45^{\circ}, 1.2 \mathrm{MeV}\right)$ according to SRIM2008 with Kinchin-Pease formalism. The characterized region depends on the thickness that can be probed by slow positrons: at most $700 \mathrm{~nm}$ for 25 $\mathrm{keV}$ [36] for PAS measured samples and about $60 \mathrm{~nm}$ for TEM observed samples.

\subsection{Characterization methods}

\subsubsection{Positron annihilation spectroscopy (PAS)}

PAS takes advantage of two fundamental properties of positrons. First, they annihilate with electrons of the solids, making it possible to probe the electronic structure of materials. Second, they can be trapped in open volumes such as vacancy-type defects (single vacancies, vacancy clusters, dislocation...), and then annihilate with surrounding electrons, enabling the detection of the nature and concentration of the defects. In the present work, a slow positron beam was coupled to a Doppler Broadening spectrometer (SPB-DB) developed at CEMHTI (Conditions Extrêmes et Matériaux: Haute Température et Irradiation). This device exhibits high efficiency in the characterization of tiny vacancytype defects in the first micron under the surface of solid samples (see [37] for further technical details). In the SPB-DB experiment, a monoenergetic positron beam produced by a 22 -sodium source is guided onto the sample, where it appears as a $2-3 \mathrm{~mm}$ spot. At the same time, it is accelerated with adjustable energy ranging from 0.5 to $25 \mathrm{keV}$ which allows an effective probing of vacancy-type defects within increasing depth. For the energy ranges from 0.5 to $25 \mathrm{keV}$, the slow positrons probe until $700 \mathrm{~nm}$ in tungsten. The implantation profile of monoenergetic positrons is a Makhovian type [36]. When the 
positrons have lost their kinetic energy, the thermalized positrons diffuse in the material and end up by annihilating with electrons, emitting in most cases two $\gamma$-rays with an energy of $511 \pm \Delta \mathrm{E}_{\gamma} \mathrm{keV}$. The energy deviation $\Delta \mathrm{E}_{\gamma}$ is proportional to the longitudinal kinetic momentum of the $\mathrm{e}^{+}-\mathrm{e}^{-}$pairs just before the annihilation and causes Doppler Broadening (DB) of the annihilation line. The DB spectrum is the photon count number as a function of their energy, i.e. the $\mathrm{e}^{+}-\mathrm{e}^{-}$pairs' kinetic momentum, and is also called the $\mathrm{e}^{+}-\mathrm{e}^{-}$annihilated pairs momentum distribution. Its shape depends on the positron states where it annihilates, i.e. either it is delocalized in the lattice or trapped at a vacancy-type defect. When a positron is trapped at a vacancy-type defect, the probability of it annihilating with core electrons or high momentum electrons is decreased compared to the case where it is delocalized in the lattice. The measured DB spectrum of material with vacancy-type defects is, therefore, thinner than that of a defect-free one. Two line-shape parameters $S$ and $W$ were used to quantify the evolution of the DB spectrum. $S$ and $W$ were respectively the low and high momentum annihilation fractions. They were equal to the ratio of photon counts in the central region close to $511 \mathrm{keV}$ and in the two wing regions respectively of the DB spectrum over the total counts of the full spectrum. $S$ is related to the positron annihilations with mostly valence electrons. $W$ is associated with annihilation which occurs mainly between positrons and core electrons. In this study, the momentum ranges chosen for the calculation of $S$ and $W$ were $0-|2.64| \times 10^{-3} \mathrm{~m}_{0} \mathrm{C}$ and $(|9.80|-|24.88|) \times 10^{-3} \mathrm{~m}_{0} \mathrm{c}\left(\mathrm{m}_{0}\right.$ : electron mass, $\mathrm{c}$ : light speed). Since the surrounding electrons of positrons trapped in open volumes are mainly valence electrons with low momentum, the annihilation that occurs at vacancy-type defects leads to an increase in $S$ and a decrease in $W$, in contrast to the annihilation taking place in the delocalized perfect lattice. It is crucial to point out that each annihilation state can be brought out with specific values of $S$ and $W$ in each material: that is why the curve $S(W)$ exhibits the nature of the principal annihilation states. Regarding tungsten, as shown in Figure 3, the specific values for a perfect lattice $\left(S_{L}=0.367(4), W_{L}=0.084(5)\right)$ and single vacancies $\left(S_{v_{1}}=0.417(1), W_{v 1}=0.057(1)\right)$ were determined in previous work [38,39], as well as those of vacancy-clusters $\left(S_{V N}=0.503(1), W_{V N}=0.036(1)\right)$ [39] which concerns probably the largest clusters detectable in our SPB-DB experiments performed in tungsten. The $S_{V N}, W_{V N}$ values were 
measured in $\mathrm{W}$ irradiated with $20 \mathrm{MeV}-\mathrm{W}$ ions with a fluence of $3.7 \times 10^{14} \mathrm{~W}^{+} . \mathrm{cm}^{-2}$ (1dpa) and postannealed at $550{ }^{\circ} \mathrm{C} / 1 \mathrm{~h}$. It can be shown that the annihilation characteristics no longer change when the number of vacancies in the cluster increases above a threshold. It has been found from positron lifetime calculations [40] that this threshold is approximately 20 to 30 in tungsten. The diameter of a cluster of 27 monovacancies in $\mathrm{W}$ was evaluated to be $0.94 \mathrm{~nm}$ for $\mathrm{N}=27$ if no relaxation occurs [41]. This suggests that the $S_{V N}, W_{V N}$ values could correspond to annihilation at such vacancy clusters made of at least 20-30 vacancies i.e. a diameter of approximately $1 \mathrm{~nm}$. Moreover, it has been demonstrated that, in the $S(W)$ graph, the absolute value of the slope of the segment lines $R\left(=\left\|\frac{S_{V n}-S_{L}}{W_{V n}-W_{L}}\right\|\right)$ linking the lattice point $\left(S_{L}, W_{L}\right)$ to that of the defect $V_{n}\left(S_{V_{n}}, W_{V_{n}}\right)$, where $\mathrm{n}$ is the number of vacancies in the vacancy cluster $(n=1,2,3 .$.$) , increases with n$ or the size of vacancy clusters. The $(S, W)$ points located at the same line going through the lattice point indicate that only one defect or the same size defect distribution with various global concentration is detected. For instance, in Figure 3 , the line $L_{1}$ indicates annihilation at single vacancies and the line $L_{2}$ indicates vacancy clusters. If we assume that the annihilation rate is $100 \%$ (in the lattice or the defect), it is clear that, at the same line, the closer the $(S, W)$ point is to the defect characteristic point $\left(S_{V_{n}}, W_{V_{n}}\right)$, the higher the concentration is.

In the SPB-DB measurement, the DB spectrum is recorded as a function of positron energy E. One high purity germanium detector with about $10 \%$ dead time offers a high resolution ( $<1.3 \mathrm{keV}$ at $511 \mathrm{keV}$ ) and detection efficiency ( $>25 \%$ at $1.33 \mathrm{MeV}$ ) of the $y$-rays. To obtain valid statistics, at least $4 \times 10^{5}$ counts are cumulated for each positron energy in the Doppler peak -in the region of momentum between -24.88 to $+24.88 \times 10^{-3} \mathrm{~m}_{0} \mathrm{c}-$ and $S, W$ values are extracted from each spectrum. In addition to the $S(W)$ plot, the curves $S$ and $W$ as a function of positron energy $E, S(E)$, and $W(E)$ respectively, illustrate the depth distribution of the vacancy-type defects. Furthermore, using the VEPTFIT program [42] the $S W$ depth profiles can be extracted from the $S(E)$ and $W(E)$ curves by fitting the experimental data. The program calculates the $S(E)$ and $W(E)$ by taking into account the implantation profiles and diffusion of positrons using a model that considers the solids as a sequence of several homogenous 
layers with independent $S$ and $W$ annihilation characteristics, thickness, and positron effective diffusion length $L_{e f f}^{+}$for each layer. Note that the diffusion of positrons is limited by their trapping at defects. Hence, the effective diffusion length $L_{e f f}^{+}$can be written as follows [43]:

$$
L_{e f f}^{+}=\sqrt{\frac{D^{+}}{\lambda_{L}+\sum_{i=1}^{n} K_{d_{i}}}}
$$

where $K_{d i}$ are the positron trapping rates at various detected defects $i$ (single vacancy, vacancy clusters $V_{N}$, dislocations, etc.), $D^{+}$is the intrinsic positron diffusion coefficient $\left(D^{+}=1.26 \times 10^{-4} \mathrm{~m}^{2} . \mathrm{s}^{-1}\right.$ for tungsten [44]) and $\lambda_{L}$ the lattice annihilation rate $\left(\lambda_{L}=1 / \tau_{L}, \tau_{L}=101-105\right.$ ps [45]). The trapping rate $K_{d}$ at the detected defects $d$ is the product of their concentration $C_{d}$ and their specific trapping coefficient $\mu_{d}$. The trapping coefficient of single vacancies in tungsten is approximated to the value determined for the single vacancy in tantalum which presents a similar atomic number $(Z=73)\left(\mu_{v}=6 \pm 3 \times 10^{-15}\right.$ $\left.\mathrm{m}^{3} \cdot \mathrm{s}^{-1}[46]\right)$. It is expected that the specific trapping coefficient for vacancy clusters $V_{N}$ is about $1.6 \times$ $10^{-13} \mathrm{~m}^{3} \cdot \mathrm{s}^{-1}$ as it can be extrapolated from TEM and PAS measurements in aluminum [46]. It should be mentioned that data acquired at low energy below $2 \mathrm{keV}$ are disregarded in the fittings because the model used in the VEPFIT program poorly describes the positron properties for such low energies.

\subsubsection{Transmission Electron Microscopy (TEM)}

To complement PAS characterization, TEM observations of the 3N-HP and 6N-XHP samples irradiated with 1.2 MeV-W ions were performed on two instruments. A JEOL ARM200F field emission gun microscope operating at $200 \mathrm{kV}$ and equipped with double spherical aberration correctors was used for samples irradiated at $500{ }^{\circ} \mathrm{C}$. The thin lamellae irradiated at $700{ }^{\circ} \mathrm{C}$ were observed with a Philips CM20 also operating at $200 \mathrm{kV}$. Defocus series were recorded from a focus of $-0.4 \mu \mathrm{m}$ to $+0.4 \mu \mathrm{m}$. According to the microscope performance, the Fresnel contrast method was able to characterize the cavities with a diameter above $0.5 \mathrm{~nm}$. Since both the out-of-focus level and the magnification impact on the apparent size of cavities [47], all TEM observations were carried out in comparable conditions, i.e. acceleration voltage and magnification. The sizing of cavities was performed on over-focused 


$$
\Delta D=D \times\left(\frac{\Delta N}{N}+\frac{\Delta t}{t}\right)
$$

224 where $\Delta D$ is the total uncertainty of the density $D$ and $\frac{\Delta t}{t}$ is the error on the thickness $t$ measurement equal to the ratio of uncertainty over measured thickness. 


\subsection{PAS results}

Figure 3 (a) shows the low momentum annihilation fraction $S$ as a function of positron energy $E$ in

tungsten samples of two purities, $3 \mathrm{~N}-\mathrm{HP}$ and $6 \mathrm{~N}-\mathrm{XHP}$, before and after irradiation at various conditions

(room temperature $(\mathrm{RT}), 500^{\circ} \mathrm{C}$ and $700{ }^{\circ} \mathrm{C}$ ). It should be pointed out that the $W(E)$ curves are the

reverse of the $S(E)$ and consequently they are not shown in Figure 3 . The results of the experimental and RT irradiated samples because they are smaller than the size of the symbols.

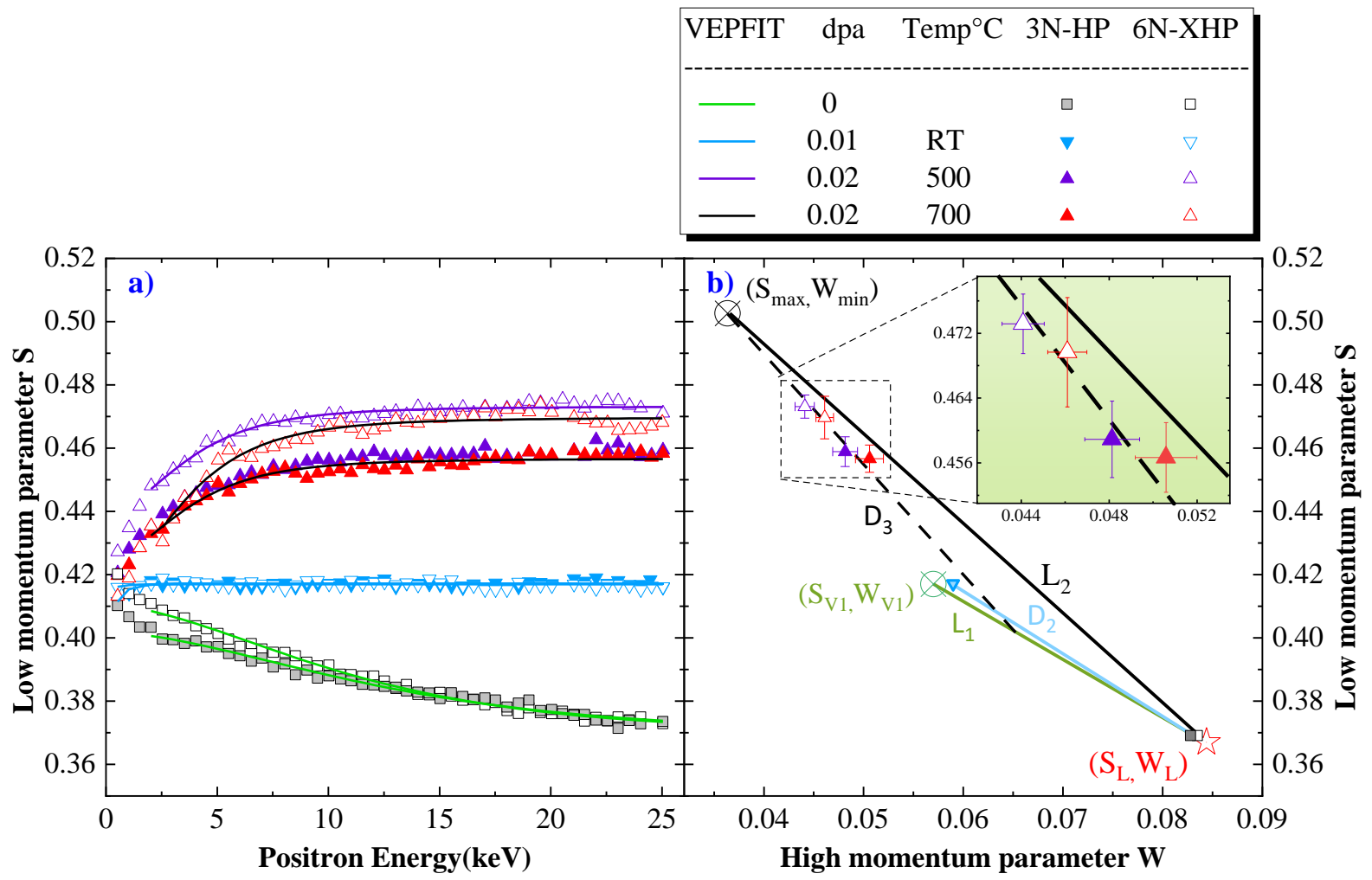

Figure 3: a: Low momentum annihilation fraction $S$ as a function of positron energy and $\boldsymbol{b}$ : the fit extracted values $S$ as a function of the high momentum annihilation fraction W ones in $3 N-H P$ W samples (solid symbols) 
For virgin $\boldsymbol{W}$ samples, the slow decrease in $S$ with increasing positron energy indicates that a

243 considerable fraction of positrons diffuse back to the surface. These experimental data of the two

244 virgin samples can be fitted with VEPFIT by using a single homogenous layer model. The $S$ and $W$ characteristics found in this layer are very similar for both types of materials 3N-HP and 6N-XHP (Table 2), and the effective diffusion length is long in both cases (3N-HP: $L_{\text {eff }}^{+}=130 \mathrm{~nm}, 6 \mathrm{~N}-\mathrm{XHP}: L_{\text {eff }}^{+}=$ $105 \mathrm{~nm}$ ) within the range reported in the literature (between 80 and $140 \mathrm{~nm}$ ) [49] for intrinsic diffusion in polycrystalline W with a purity of $99.95 \%$.wt. Thus, the annihilation occurs both in the perfect lattice and at the surface of the samples. In Figure 3 (b), SW values extracted for both virgin materials using the VEPFIT program are close to the annihilation characteristics of the tungsten perfect

251 lattice. These results indicate that samples of both purities show similar positron annihilation 252 characteristics before irradiation and that the density of open volume defects is below the detection 253 limit of the SPB-DB (i.e. approximately $10^{24} \mathrm{~m}^{-3}$ ).

\begin{tabular}{|c|c|c|c|c|c|c|}
\hline Sample & $\begin{array}{c}\text { Purity } \\
\text { wt.\% }\end{array}$ & $\begin{array}{c}\text { Damage } \\
\text { level(dpa) }\end{array}$ & $\begin{array}{c}\text { Temperature } \\
{ }^{\circ} \mathbf{C}\end{array}$ & $\boldsymbol{S}$ & $W$ & $\begin{array}{c}\boldsymbol{L}_{\text {eff }}^{+} \\
\text {(nm) }\end{array}$ \\
\hline G-35 & 99.95 & 0 & - & $0.3690(2)$ & $0.0828(4)$ & $132(6)$ \\
\hline J-17 & 99.9999 & 0 & - & $0.3690(2)$ & $0.0835(4)$ & $105(4)$ \\
\hline G-04 & 99.95 & 0.01 & RT & $0.4172(17)$ & $0.0590(6)$ & $0.6(1.7)$ \\
\hline J-05 & 99.9999 & & & $0.4170(16)$ & $0.0590(9)$ & $0.4(0.2)$ \\
\hline G-05 & 99.95 & & & $0.4589(21)$ & $0.04814(9)$ & $17(2)$ \\
\hline J-11 & & \multirow{2}{*}{0.02} & 500 & $0.4723(38)$ & $0.0431(8)$ & $9(1)$ \\
\hline J-06 & 99.9999 & & & $0.4741(32)$ & $0.0434(14)$ & $11(2)$ \\
\hline J-15 & & & & $0.4726(37)$ & $0.0442(10)$ & $17(2)$ \\
\hline G-02 & 99.95 & 0.02 & 700 & $0.4567(43)$ & $0.0506(12)$ & $14(2)$ \\
\hline J-03 & 99.9999 & 0.02 & & $0.4697(68)$ & $0.0461(9)$ & $17(2)$ \\
\hline
\end{tabular}

After irradiation (0.01 dpa) at $\mathbf{R T}$, quasi-identical positron annihilation characteristics were found in 
indicating a homogenous distribution of induced defects in the region probed by positrons as is expected from the SRIM calculations. This was confirmed by the data fitting which required only a single layer to model the characterized region $(0-700 \mathrm{~nm})$. In Figure $3(\mathrm{~b})$, the $S$ and $W$ fitted values are linked to the lattice point (star symbol) by a dotted line $D_{2}$. The absolute value of the $D_{2}$ slope $R$ slightly exceeds that of the single vacancy line $L_{1}$, meaning that the induced defects are mostly related to small vacancy clusters $V_{n}$, the majority of which are single vacancies. As shown in table 2 , the estimated effective diffusion length $L_{e f f}^{+}$of positrons in the damaged region is extremely short $(<4 \mathrm{~nm}$ ) for both tungsten purities, indicating a very high trapping rate of positrons $K_{D}$ of about $1.5 \pm 0.5 \times 10^{14} \mathrm{~s}^{-1}$ estimated using equation (4) with an intrinsic diffusion $L^{+}$fixed at $135 \mathrm{~nm}$ [50] and a lattice positron lifetime of 105 ps [40]. That could correspond to a maximum concentration of whole vacancy defects of about $10^{27} \mathrm{~m}^{-3}$ (using a trapping coefficient of $\mu_{\mathrm{v}}=6 \pm 3 \times 10^{-15} \mathrm{~m}^{-3} \cdot \mathrm{s}^{-1}[46]$ ).

$$
K_{D}=\lambda_{L}\left[\left(\frac{L^{+}}{L_{e f f}^{+}}\right)^{2}-1\right]
$$

For irradiation (0.02 dpa) at high temperatures $\left(500^{\circ} \mathrm{C}\right.$ and $\left.700{ }^{\circ} \mathrm{C}\right)$, the $S(E)$ curves exhibit a drastic increase in $S$ below $10 \mathrm{keV}$ before reaching a plateau value. Note that for the same sample purity, the $S$ plateau values (and $W$ ones not shown here) are close for both high irradiation temperatures $500{ }^{\circ} \mathrm{C}$ and $700{ }^{\circ} \mathrm{C}$. For the same irradiation temperature, these plateau values depend strongly on the purity of W samples, indicating a meaningful difference in induced defects between the two types of samples $3 \mathrm{~N}-\mathrm{HP}$ and $6 \mathrm{~N}-\mathrm{XHP}$. The experimental data were adjusted using a single layer model (solid line in Figure 3 (a)) and the $S$ and $W$ values extracted for this damaged layer are reported in Table 2 and plotted in Figure 3 (b). In this figure, it can be observed that the SW points measured for the irradiations performed at high temperature are well above the single vacancy line $L_{1}$, clearly indicating that large vacancy clusters were formed. Moreover, it was found that the $S W$ points for the irradiation performed at 500 and $700{ }^{\circ} \mathrm{C}$ are very close, even if, for irradiation at $700{ }^{\circ} \mathrm{C}$, the data closer to the line $L_{2}$ signifying the largest detectable vacancy cluster but It is difficult to distinguish them with those of $500{ }^{\circ} \mathrm{C}$, if we consider the measurement discrepancy for such samples. Finally, and more remarkably, at the same 
irradiation temperature, the $S W$ points measured for the purest sample $(6 \mathrm{~N}-\mathrm{XHP})$ are the furthest away from the annihilation characteristics of the single vacancy, indicating that the fraction of positrons annihilated at vacancy clusters is greater in the $6 \mathrm{~N}-\mathrm{XHP}$ than in the $3 \mathrm{~N}-\mathrm{HP}$ sample. A straight line can be plotted to go through the fitted $S W$ points in the samples irradiated at the same damage level ( $0.02 \mathrm{dpa}$ ) for $500^{\circ} \mathrm{C}$ and $700^{\circ} \mathrm{C}$, which will be denoted $\mathrm{D}_{3}$. When extending this line toward larger $S$ and lower $W$ it can be observed that it joins the $S_{V N}, W_{V N}$ point corresponding to annihilation at the largest vacancy clusters detected in tungsten. When elongating $D_{3}$ to the lower $S$ and larger $W$, the line does not coincide with the lattice point but tends to two-thirds of the $L_{1}$ straight line segment from the lattice point. As shown in Table 2, the estimated effective diffusion length $L_{e f f}^{+}$of positrons in the damaged region is quite short (between 9 and $17 \mathrm{~nm}$ ) for all irradiation conditions and tungsten purities. From equation 4, we can deduce a high trapping rate $\mathrm{K}$ of positrons of about $1 \times 10^{12} \mathrm{~s}^{-1}$ for the mean value of the estimated effective diffusion length $L_{e f f}^{+}$of $13 \mathrm{~nm}$. It follows that the fraction of positrons annihilated in the delocalized state, i.e. the perfect lattice, is negligible $(<1 \%)$. Moreover, the SW points of irradiated samples are located well below the annihilation characteristics of the largest vacancy clusters $V_{N}$ containing 20 - 30 vacancies or with a diameter equal to or greater than 1 $\mathrm{nm}$. This indicates that positrons either detected mainly vacancy clusters with a diameter smaller than that of $V_{N}$-i.e. $1 \mathrm{~nm}$ - or that positrons are trapped and annihilate at different vacancy defects, i.e. the vacancy clusters $V_{N}$ and a defect for which the annihilation characteristics $S W$ are not yet known but which should be located on the $D_{3}$ line. We will denote this defect $D_{x}$ in the following discussion. Consequently, in the first case, the trapping rate is equal to $\mathrm{K}_{\mathrm{v}_{n}}$ which means the trapping rate at $\mathrm{V}_{\mathrm{n}}$ vacancy clusters (which are smaller than $V_{N}$ ones). In the second case, $\mathrm{K}$ is the sum of two trapping rates, $\mathrm{K}_{\mathrm{VN}}$, for trapping at $\mathrm{V}_{\mathrm{N}}$, and $\mathrm{K}_{\mathrm{DX}}$ for trapping at $\mathrm{D}_{\mathrm{x}}$. We will discuss both cases in section 4.

\subsection{TEM results}

To characterize the larger vacancy-type defects, i.e. cavities, we directly performed observations using two different TEM microscopes with the same acceleration voltage and comparable magnification. Figure 4 shows the typical over-focused images $(+300 \mathrm{~nm})$ of the $3 \mathrm{~N}-\mathrm{HP}$ and $6 \mathrm{~N}-\mathrm{XHP}$ tungsten samples 
self-irradiated to $0.02 \mathrm{dpa}$ at $500{ }^{\circ} \mathrm{C}$ and $700{ }^{\circ} \mathrm{C}$. The identification and counting of the cavities were

311 performed in only one over- and under-focused image pair for the samples irradiated at $500^{\circ} \mathrm{C}$ (Figure 4 a-b). For the samples irradiated at $700{ }^{\circ} \mathrm{C}$, the over- and under-focused images were recorded in several adjacent zones in the same grain, and the cavities were counted in 4 images (Figure $4 \mathrm{c}-\mathrm{f}$ ) for $3 \mathrm{~N}-\mathrm{HP}$ and 2 images (Figure $4 \mathrm{~g}-\mathrm{h}$ ) for $6 \mathrm{~N}-\mathrm{XHP}$ to ensure a reliable statistical analysis. For the 3N-HP sample irradiated at $500^{\circ} \mathrm{C}$, because of a low contrast quality, an area with a low distribution of cavities included in the $20 \mathrm{~nm}$ on the left side of figure 4a (red mask) was not taken into account and was removed from the probed volume. The size distribution of cavities, i.e. the number counted as a function of the diameter measured, was plotted and superimposed on the images in Figure 4. A total number of 491 and 479 cavities were counted for the $3 \mathrm{~N}-\mathrm{HP}$ sample irradiated at $500{ }^{\circ} \mathrm{C}$ and $700{ }^{\circ} \mathrm{C}$ respectively, and $1015\left(500^{\circ} \mathrm{C}\right)$ and $346\left(700^{\circ} \mathrm{C}\right)$ for the $6 \mathrm{~N}$-XHP one. Table 3 summarizes the mean diameters and the density of counted cavities in 3N-HP and 6N-XHP for both irradiation temperatures. The centroid of a Gaussian fitting was considered as the mean diameter of the cavities. The effective analyzed surface was multiplied by the corresponding thickness to assess the volumetric density of the cavities in the probed region. The corresponding errors on the diameter and density were estimated by using equations 1 and 2 in section 2.2 .2 . For irradiation at $500^{\circ} \mathrm{C}$, the cavity density was comparable for both purities at about $1.6 \pm 0.5 \times 10^{24} \mathrm{~m}^{-3}$. It remained very close for both purities when the irradiation temperature increased to $700^{\circ} \mathrm{C}$, but decreased by approximately a factor of $2(0.65 \pm 0.5$ $\times 10^{24} \mathrm{~m}^{-3}$ ) for the highest temperature. Regarding the diameter, whatever the irradiation temperature, the mean value of the $3 \mathrm{~N}-\mathrm{HP}$ sample (about $0.97 \mathrm{~nm}$ ) was slightly lower than that of the 6N-XHP sample (1.13 - $1.22 \mathrm{~nm}$ for $500{ }^{\circ} \mathrm{C}$ and $700{ }^{\circ} \mathrm{C}$, respectively). Furthermore, a large number of cavities with a diameter above $1 \mathrm{~nm}$ were counted in the $6 \mathrm{~N}-\mathrm{XHP}$ sample ( $82 \%$ for $500{ }^{\circ} \mathrm{C}$ and $87 \%$ for $700^{\circ} \mathrm{C}$ ), in contrast to the $3 \mathrm{~N}$-HP samples $\left(22 \%\right.$, for $500^{\circ} \mathrm{C}$ and $36 \%$ for $700{ }^{\circ} \mathrm{C}$ ). This indicates that larger cavities are observed in $6 \mathrm{~N}-\mathrm{XHP}$ samples for both irradiation temperatures ( 500 and $700^{\circ} \mathrm{C}$ ) as is clearly shown in Figure 5, where the total cavity size distributions are plotted for all the samples for the irradiations performed at $500^{\circ} \mathrm{C}$ (Figure 5a) and $700^{\circ} \mathrm{C}$ (Figure 5b). Besides, assuming that the cavities are spherical, 
337 the total analyzed volume. The local swelling due to cavities was estimated to be between 338 approximately $0.1 \%$ in $6 \mathrm{~N} \_\mathrm{XHP}$ irradiated at $500^{\circ} \mathrm{C}$ and $0.04 \%$ for $3 \mathrm{~N}-\mathrm{HP}$ irradiated at $700{ }^{\circ} \mathrm{C}$. For both irradiation temperatures, larger local swelling was obtained in 6N-XHP samples than in 3N-HP ones.
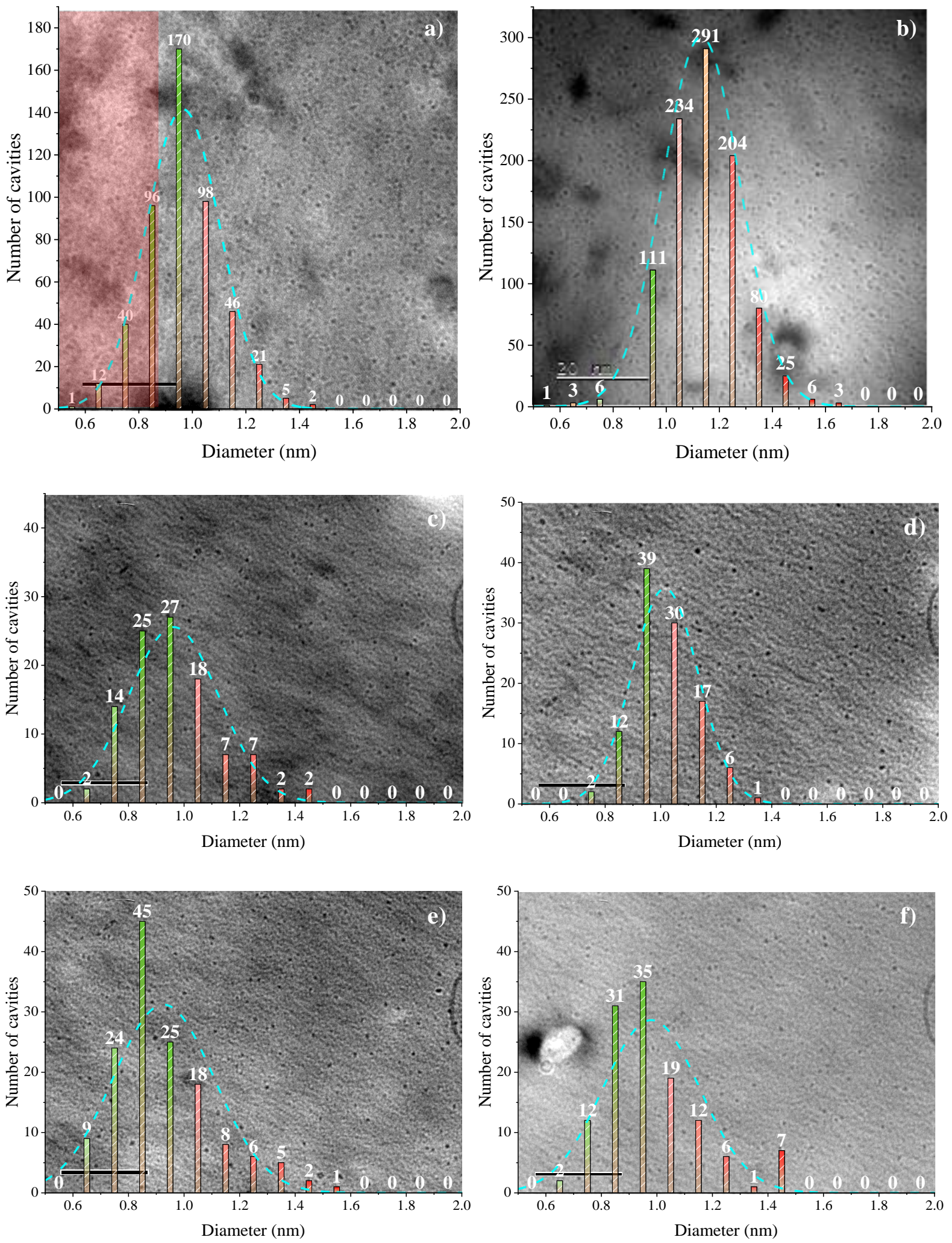

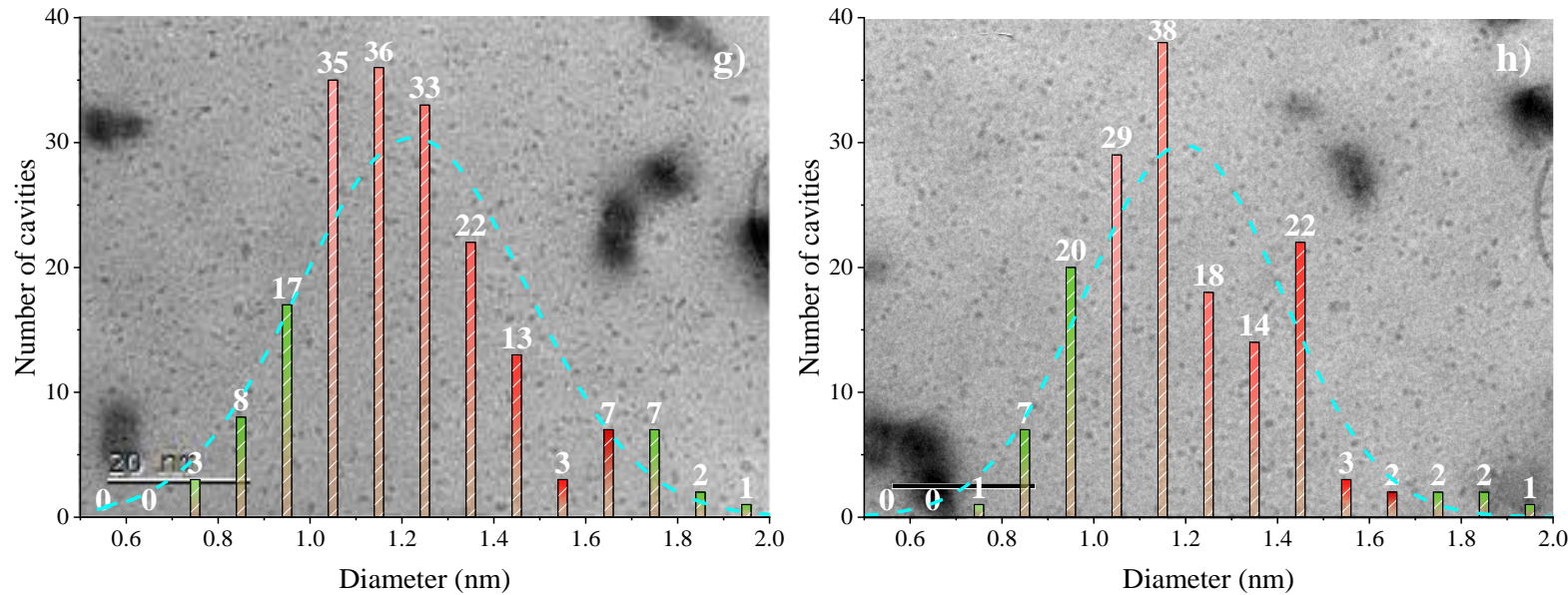

Figure 4: Over focused (+300 $\mathrm{nm}$ ) images a) 3N-HP sample and b) 6N-XHP sample irradiated at $500{ }^{\circ} \mathrm{C}(0.02 \mathrm{dpa})$

observed by a JEOL ARM20OF cold field emission gun microscope and Over-focus (+300 nm) image c-f) 3N-HP

sample and $\mathbf{g}$-h) $6 \mathrm{~N}$-XHP sample irradiated at $700{ }^{\circ} \mathrm{C}(0.02 \mathrm{dpa})$ observed by a Philips CM20 microscope. The size distributions of cavities are superimposed on their respective images and were fitted by a Gaussian function (cyan dashed line).
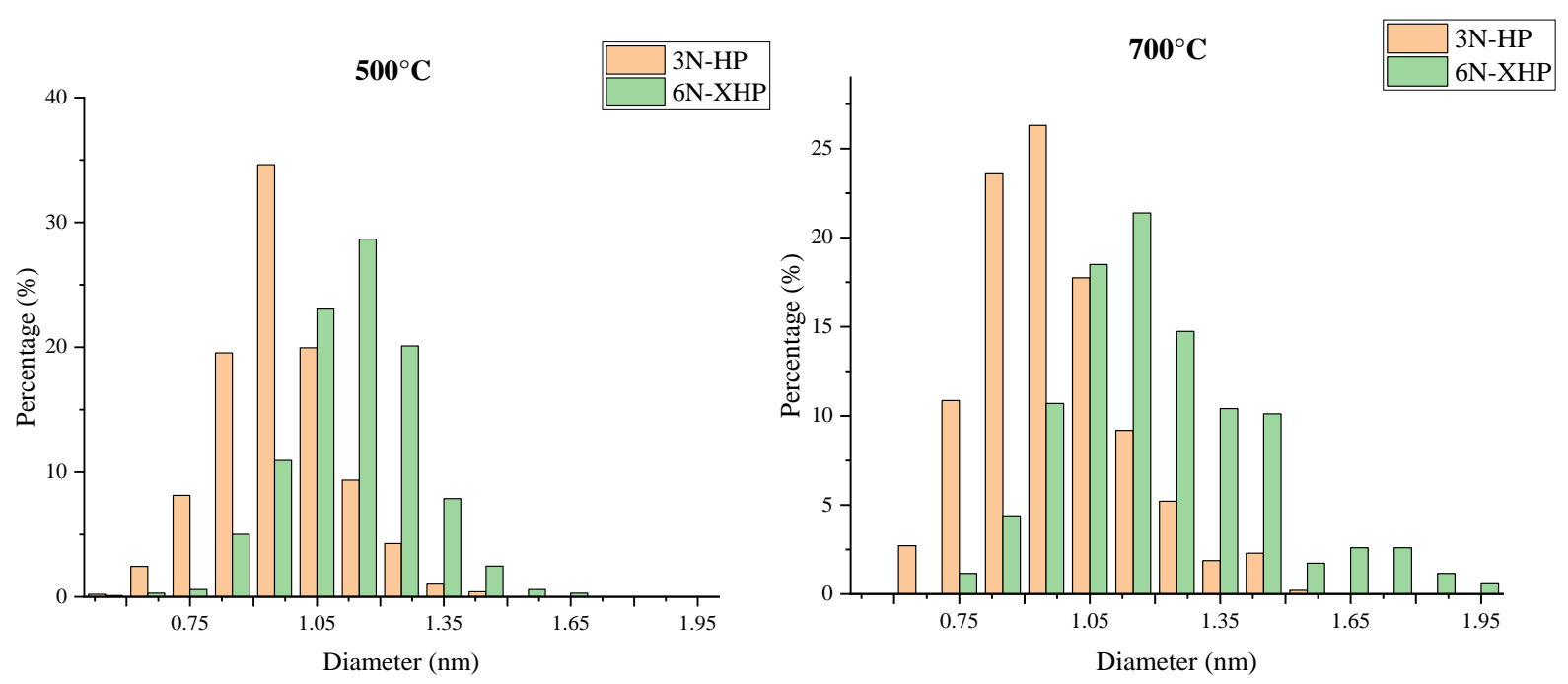


\begin{tabular}{c|cc|cc} 
Damage level (dpa) & \multicolumn{5}{c}{0.02} \\
\hline Observation conditions & \multicolumn{2}{|c|}{ JEOL ARM200, $200 \mathrm{kV}, 500 \mathrm{kX}}$, & \multicolumn{2}{c}{ Philips CM20, 200 kV, 500 kX } \\
Irradiation Temperature $\left({ }^{\circ} \mathrm{C}\right)$ & \multicolumn{2}{|c}{500} & \multicolumn{2}{c}{700} \\
Purity & $3 \mathrm{~N}-\mathrm{HP}$ & $6 \mathrm{~N}-\mathrm{XHP}$ & $3 \mathrm{~N}-\mathrm{HP}$ & $6 \mathrm{~N}-\mathrm{XHP}$ \\
\cline { 2 - 5 } & $55 \pm 20$ & $90 \pm 30$ & $35 \pm 20$ & $60 \pm 50$ \\
Thickness $(\mathrm{nm})$ & $(\mathrm{EFTEM})$ & $(\mathrm{EFTEM})$ & (evaluated) & (evaluated) \\
Mean diameter $(\mathrm{nm})$ & $0.97 \pm 0.19$ & $1.13 \pm 0.21$ & $0.97 \pm 0.25$ & $1.22 \pm 0.25$ \\
Density $\left(10^{24} \mathrm{~m}^{-3}\right)$ & $1.73 \pm 0.71$ & $1.56 \pm 0.52$ & $0.70 \pm 0.42$ & $0.60 \pm 0.53$ \\
Swelling $\%$ & $0.09 \pm 0.02$ & $0.12 \pm 0.04$ & $0.04 \pm 0.02$ & $0.08 \pm 0.05$
\end{tabular}

Table 3: The mean diameters of cavities observed by TEM and their density in irradiated 3N-HP and 6N-XHP

\section{samples and the measured or evaluated thickness}

\section{Discussion}

PAS exhibits the formation of vacancy-type defects in self-irradiated tungsten at a low damage dose of 0.01 to $0.02 \mathrm{dpa}$. The nature of these defects changes with the irradiation temperature and whereas mainly single vacancies are detected for irradiation at RT, a large fraction of positron annihilates as trapped at vacancy clusters when irradiation is performed at 500 and $700^{\circ} \mathrm{C}$. TEM observations confirmed the presence of cavities for these irradiation conditions. The formation of the vacancy clusters or cavities is probably the result of the migration of single vacancies of tungsten and their agglomeration which becomes possible at such high temperatures considering the migration energy of the single vacancy $\left(E_{m}(V)=1.66 \mathrm{eV}[31]\right)$. This agglomeration has been already observed after the annealing of irradiated tungsten with $800 \mathrm{keV}{ }^{3} \mathrm{He}$ at RT when the annealing temperature exceeds $350{ }^{\circ} \mathrm{C}[38,51]$. As explained in section 3.1 , the $S W$ values obtained in samples irradiated at 500 and $700{ }^{\circ} \mathrm{C}$ could correspond to either $100 \%$ of annihilation in vacancy clusters with a diameter below 1 $\mathrm{nm}$, or to a competition of annihilation in at least two types of vacancy defects, i.e. the vacancy clusters $V_{N}$ and a defect $D_{x}$ for which the annihilation characteristics are not yet known and which should be located on the $D_{3}$ line. TEM detects vacancy clusters or cavities with a mean diameter of about $1 \mathrm{~nm}$, which eliminates the first hypothesis. It can be concluded that the positrons are sensitive to a defect $D_{x}$ that cannot be detected in TEM. It follows that the differences between the PAS results obtained in $3 \mathrm{~N}-\mathrm{HP}$ and $6 \mathrm{~N}-\mathrm{XHP}$ samples can be explained by a lower fraction of annihilation in the vacancy clusters $V_{N}$ in $3 \mathrm{~N}-\mathrm{HP}$ than in $6 \mathrm{~N}-\mathrm{XHP}$, in other words, a higher fraction of annihilation in $\mathrm{D}_{\mathrm{x}}$ is revealed in $3 \mathrm{~N}-\mathrm{HP}$ 
samples. The nature of these defects is discussed in the following. First, since the two techniques show that the agglomeration of small vacancies was impeded in 3N-HP samples compared to 6N-XHP ones, it is reasonable to pay attention to the LEs in the samples, such as $\mathrm{H}, \mathrm{C}, \mathrm{N}$ and $\mathrm{O}$ considering their properties in tungsten and their strong interactions with vacancy-type defects (see Table 1). As shown in Table 4, since the 6N-XHP was analyzed by LA-ICP-MS, the quantity of the LEs could not be detected. Regarding the 3N-HP sample, an obvious and large quantity of LEs was recorded, suggesting a higher concentration of LEs that ranges between 130 to 910 at. ppm, within in particular 460 at. ppm of carbon in 3N-HP samples. These LEs have low migration energy in tungsten, which indicates their high mobility under the irradiation conditions performed in this study. Furthermore, they can be linked firmly with a single vacancy leading to the formation of V-LE complexes owing to their high binding energy. Thus, such V-LE complexes could be formed in tungsten when the irradiation temperature is high enough to allow the migration of either LEs or of the single vacancies, which is the case for both from $500^{\circ} \mathrm{C}$. In these complexes, the most favorable occupation site for $\mathrm{C}, \mathrm{N}$, and $\mathrm{O}$ atoms is in the vicinity of a single vacancy, at a distance of about $1.3 \AA$ from the vacancy's center close to an octahedral site $[25,26,29]$. Their theoretical dissociation energies are given in Table 4, i.e. the sum of the migration of the most mobile species of the complexes and the binding energies. A high value was calculated for carbon (3.39 eV), nitrogen $(3.21 \mathrm{eV})$, and oxygen $(3.22 \mathrm{eV})$, but it was only $1.4 \mathrm{eV}$ for hydrogen. Consequently, for the cases of $\mathrm{C}, \mathrm{O}$, and $\mathrm{N}$, the complexes should be stable even though the irradiation is performed at $500{ }^{\circ} \mathrm{C}$ and $700{ }^{\circ} \mathrm{C}$, whereas the $\mathrm{V}-\mathrm{H}$ complexes should be dissociated at high temperatures. However, such complexes cannot be detected by TEM because of their size. Positrons, however, should be sensitive to these complexes because the LE atoms are not trapped in the center of the vacancy and leave some space with a lower electron density than in the lattice of the W. The annihilation characteristics $S_{D x}$ and $W_{D x}$ of these complexes should be different from those of single vacancies and manifested by a lower $S$ and higher $W$ due to the electronic density which is higher in the complex than in an empty single vacancy. Therefore, the $S_{D x}, W_{D x}$ point should be on the lower part of the $D_{3}$ line. 


\begin{tabular}{|c|c|c|c|c|c|}
\hline \multirow{2}{*}{$x$} & \multicolumn{2}{|c|}{ at. ppm } & \multirow{2}{*}{$\begin{array}{c}\boldsymbol{E}_{\boldsymbol{m}}^{\boldsymbol{X}} \\
(\mathrm{eV})\end{array}$} & \multirow{2}{*}{$\begin{array}{c}\boldsymbol{E}_{\boldsymbol{b}}^{\mathbf{V}-\boldsymbol{X}_{\mathbf{1}}} \\
(\mathrm{eV})\end{array}$} & \multirow{2}{*}{$\begin{array}{c}E_{\text {diss }}^{V-X_{1}} \\
(\mathrm{eV})\end{array}$} \\
\hline & $3 \mathrm{~N}-\mathrm{HP}$ & $6 \mathrm{~N}-\mathrm{XHP}$ & & & \\
\hline$H$ & 910 & Ud & 0.21 (TIS-TIS) [27] & $1.24[28]$ & 1.45 \\
\hline C & 460 & Ud & 1.46 (TIS-OIS) [23] & 1.93 [23] & 3.39 \\
\hline$N$ & 130 & Ud & 0.73 (TIS-OIS) [29] & $2.48[24]$ & 3.21 \\
\hline 0 & 345 & Ud & 0.17 (TIS-TIS) [25] & $3.05[25]$ & 3.22 \\
\hline
\end{tabular}

Table 4: Elementary composition in the 3N-HP and 6N-XHP sample from the supplier (Ud: undetectable), and the most favorable calculated value of migration energy $E_{m}^{X_{1}}$ of element $X$ and its binding energy $E_{b}^{V-X_{1}}$ with a tungsten single vacancy. The most favorable inter-site migration (TIS: tetrahedral interstitial site, OIS:

octahedral interstitial site). The dissociation energy of the $V$ - $X_{1}$ complex is $E_{\text {diss }}^{V-X_{1}}=E_{m}^{i}+E_{b}^{V-X_{1}}$ where $i$ is the most mobile species between $V$ and $X$.

The formation of these V-LE complexes could be more efficient in the less pure material (3N-HP) than in the purer one (6N-XHP). These complexes could impede the migration of some single vacancies that can migrate and join the vacancy clusters, contributing to their growth in the less pure tungsten $(3 \mathrm{~N}$ HP), as it has been shown in carbon-doped Fe for the V-C complex [24]. In addition, Asoka-Kumar et al. [52] and Rementeria et al. [53] showed two examples of the effect of the $C$ trapping at vacancies on the electron momentum distribution probed by positrons in Fe based alloys, in fatigued type 304 stainless steel and in bainite phase of Fe-0.66C-1.45Si-1.35Mn-1.02Cr-0.10Ni-0.24Mo alloy respectively. The carbon effect was evident at around $10 \times 10^{-3} \mathrm{~m}_{0} \mathrm{c}$, which is included in the $\mathrm{W}$ region of our SPB-DB measurement.

The nature of the complexes cannot be determined from the data presented in this study. It could be $\mathrm{V}-\mathrm{C}_{\mathrm{n}}, \mathrm{V}-\mathrm{N}_{\mathrm{n}}, \mathrm{V}-\mathrm{O}_{\mathrm{n}}$, or $\mathrm{V}-\mathrm{C}-\mathrm{H}$ as predicted by simulation, although the number of LE atoms in the complexes cannot be specified. Nevertheless, the number of bound LEs $\mathrm{n}$ should be low enough to make positron trapping at V-LE complexes still possible. If we consider the density of vacancy clusters or cavities $V_{N}$ observed in TEM of about $(1.6 \pm 0.5) \times 10^{24} \mathrm{~m}^{-3}$ and the trapping coefficient of the positron at $V_{N}$ of about $1.6 \times 10^{-13} \mathrm{~m}^{3} \cdot \mathrm{s}^{-1}$ as given in reference [46], then the trapping rate at $V_{N}$ can be estimated to be about $3 \times 10^{11} \mathrm{~s}^{-1}$. From the total trapping rate estimated from the positron effective diffusion length, the trapping rate at defects $D_{x}$ is $5 \times 10^{11} \mathrm{~s}^{-1}$. Considering that the trapping coefficient at defects 
$D_{x}$ is close to that of single vacancies, i.e. $\mu_{v}=6 \pm 3 \times 10^{-15} \mathrm{~m}^{-3} \cdot \mathrm{s}^{-1}[46]$, the concentration of $D_{x}$ could be about $7 \times 10^{25} \mathrm{~m}^{-3}$ (i.e. about 1200 at. ppm). These values are of the same order of magnitude as the total C, N, and O concentrations in $3 \mathrm{~N}-\mathrm{HP}$ samples (935 at. ppm).

\section{Summary}

In this work, we performed PAS and TEM to characterize the vacancy-type defects induced by selfirradiation in tungsten as a function of its purity and the irradiation temperature. The two techniques consistently indicate a clear effect of the purity on the vacancy-type defect behaviors as a function of irradiation temperature. At RT, PAS characterization revealed an equivalent homogenous distribution of small vacancy clusters in the samples of two different purities. However, an obvious purity effect was observed at $500{ }^{\circ} \mathrm{C}$ and $700{ }^{\circ} \mathrm{C}$ with the damage level (0.02 dpa). TEM characterization showed larger cavities in the higher purity samples than in the lower purity ones, with a drastically increasing number of cavities with diameters above $1 \mathrm{~nm}$. The PAS results revealed at least two different positron traps: (1) large vacancy clusters $V_{N}$ and (2) $D_{x}$ vacancy defects. A greater fraction of annihilation at defects $D_{x}$ was observed in lower purity samples. These consistent results can be compared to the properties of the LEs (carbon, oxygen, nitrogen) in tungsten and in particular to their high propensity to be bound to a single vacancy. This could suggest that the formation of V-LE complexes could impede the clustering of vacancies in lower purity material. Further annealing experiments and qualitative measurements such as positron lifetime spectroscopy (PALS), atom probe tomography (APT), or SIMS will be performed to identify in greater detail the nature of the complexes.

\section{Credit authorship contribution statement}

Zhiwei Hu: Sample preparation, SPB-DB experiment, PAS and TEM data processing and analysis, Writing - original draft \& editing. Pierre Desgardin: Supervision, SPB-DB equipment Cécile Genevois: Supervision, TEM experiments Jérôme Joseph: Sample preparation and equipment support Brigitte Décamps \& Robin Schäublin: TEM analysis methodology and in situ irradiations Marie-France Barthe: Conceptualization, contribution to the in situ irradiations, supervision, review \& editing.

\section{Declaration of Competing Interest}

The authors declare that they have no known competing financial interests or personal relationships that could have appeared to influence the work reported in this paper. 


\section{Acknowledgments}

450

451

452

453

454

455

456

457

458

459

460

461

462

463

464

465

466

467

468

469

470

471

472

473

474

475

476

477

478

479

480

481

482

483

484

485

486

487

488

This work was carried out within the framework of the EUROfusion Consortium and received funding from the Euratom research and training program 2014-2020 under grant agreement No 633053. The views and opinions expressed herein do not necessarily reflect those of the European Commission. The authors thank the JANNuS platform staff (Joint Accelerators for Nanoscience and Nuclear Simulation), Orsay and Saclay, France for their assistance in the irradiations and the ICMN laboratory (Orléans, France) for access to the CM20 microscope. This project is co-funded by the European Union, the Region Centre Val de Loire, and the French Ministry of Research (MESRI-DRRT). Europe is committed to the Centre-Val de Loire region with the European regional development fund (ERDF).

\section{References}

[1] T. Hirai, F. Escourbiac, V. Barabash, A. Durocher, A. Fedosov, L. Ferrand, T. Jokinen, V. Komarov, M. Merola, S. Carpentier-Chouchana, N. Arkhipov, V. Kuznetcov, A. Volodin, S. Suzuki, K. Ezato, Y. Seki, B. Riccardi, M. Bednarek, P. Gavila, Status of technology R\&D for the ITER tungsten divertor monoblock, J. Nucl. Mater. 463 (2015) 1248-1251.

https://doi.org/10.1016/j.jnucmat.2014.12.027.

[2] T. Hirai, S. Panayotis, V. Barabash, C. Amzallag, F. Escourbiac, A. Durocher, M. Merola, J. Linke, Th. Loewenhoff, G. Pintsuk, M. Wirtz, I. Uytdenhouwen, Use of tungsten material for the ITER divertor, Nucl. Mater. Energy. 9 (2016) 616-622. https://doi.org/10.1016/j.nme.2016.07.003.

[3] T. Hirai, V. Barabash, F. Escourbiac, A. Durocher, L. Ferrand, V. Komarov, M. Merola, ITER divertor materials and manufacturing challenges, Fusion Eng. Des. 125 (2017) 250-255. https://doi.org/10.1016/j.fusengdes.2017.07.009.

[4] S. Pestchanyi, F. Maviglia, Simulation of the first wall shielding during upward VDE in DEMO, Nucl. Mater. Energy. 24 (2020) 100767. https://doi.org/10.1016/j.nme.2020.100767.

[5] S. Kajita, W. Sakaguchi, N. Ohno, N. Yoshida, T. Saeki, Formation process of tungsten nanostructure by the exposure to helium plasma under fusion relevant plasma conditions, Nucl. Fusion. 49 (2009) 095005. https://doi.org/10.1088/0029-5515/49/9/095005.

[6] S. Takamura, N. Ohno, D. Nishijima, S. Kajita, Formation of Nanostructured Tungsten with Arborescent Shape due to Helium Plasma Irradiation, Plasma Fusion Res. 1 (2006) 051-051. https://doi.org/10.1585/pfr.1.051.

[7] F. Ferroni, X. Yi, K. Arakawa, S.P. Fitzgerald, P.D. Edmondson, S.G. Roberts, High temperature annealing of ion irradiated tungsten, Acta Mater. 90 (2015) 380-393. https://doi.org/10.1016/j.actamat.2015.01.067.

[8] X. Yi, M.L. Jenkins, M.A. Kirk, Z. Zhou, S.G. Roberts, In-situ TEM studies of $150 \mathrm{keV} \mathrm{W+ion}$ irradiated $\mathrm{W}$ and $\mathrm{W}$-alloys: Damage production and microstructural evolution, Acta Mater. 112 (2016) 105-120. https://doi.org/10.1016/j.actamat.2016.03.051.

[9] J. Heikinheimo, K. Mizohata, J. Räisänen, T. Ahlgren, P. Jalkanen, A. Lahtinen, N. Catarino, E. Alves, F. Tuomisto, Direct observation of mono-vacancy and self-interstitial recovery in tungsten, APL Mater. 7 (2019) 021103. https://doi.org/10.1063/1.5082150.

[10] O.V. Ogorodnikova, L.Y. Dubov, S.V. Stepanov, D. Terentyev, Yu.V. Funtikov, Yu.V. Shtotsky, V.S. Stolbunov, V. Efimov, K. Gutorov, Annealing of radiation-induced defects in tungsten: Positron 
annihilation spectroscopy study, J. Nucl. Mater. 517 (2019) 148-151. https://doi.org/10.1016/j.jnucmat.2019.02.010.

[11] X. Hu, T. Koyanagi, M. Fukuda, Y. Katoh, L.L. Snead, B.D. Wirth, Defect evolution in single crystalline tungsten following low temperature and low dose neutron irradiation, J. Nucl. Mater. 470 (2016) 278-289. https://doi.org/10.1016/j.jnucmat.2015.12.040.

[12] C.N. Taylor, M. Shimada, B.J. Merrill, D.W. Akers, Y. Hatano, Development of positron annihilation spectroscopy for investigating deuterium decorated voids in neutron-irradiated tungsten, J. Nucl. Mater. 463 (2015) 1009-1012. https://doi.org/10.1016/j.jnucmat.2014.11.033.

[13] C.N. Taylor, M. Shimada, B.J. Merrill, M.W. Drigert, D.W. Akers, Y. Hatano, Development of positron annihilation spectroscopy for characterizing neutron irradiated tungsten, Phys. Scr. T159 (2014) 014055. https://doi.org/10.1088/0031-8949/2014/T159/014055.

[14] G. Bonny, M.J. Konstantinovic, A. Bakaeva, C. Yin, N. Castin, K. Mergia, V. Chatzikos, S. Dellis, T. Khvan, A. Bakaev, A. Dubinko, D. Terentyev, Trends in vacancy distribution and hardness of high temperature neutron irradiated single crystal tungsten, Acta Mater. 198 (2020) 1-9. https://doi.org/10.1016/j.actamat.2020.07.047.

[15] M. Sala, A. Uccello, D. Dellasega, M. Pedroni, E. Vassallo, M. Passoni, Exposures of bulk W and nanostructured W coatings to medium flux D plasmas, Nucl. Mater. Energy. (n.d.). https://doi.org/10.1016/j.nme.2020.100779.

[16] T. Suzudo, M. Yamaguchi, A. Hasegawa, Migration of rhenium and osmium interstitials in tungsten, J. Nucl. Mater. 467 (2015) 418-423. https://doi.org/10.1016/j.jnucmat.2015.05.051.

[17] C.-H. Huang, M.R. Gilbert, J. Marian, Simulating irradiation hardening in tungsten under fast neutron irradiation including Re production by transmutation, J. Nucl. Mater. 499 (2018) 204-215. https://doi.org/10.1016/j.jnucmat.2017.11.026.

[18] A. Hasegawa, Property change mechanism in tungsten under neutron irradiation in various reactors, J. Nucl. Mater. (2011) 4.

[19] A. Hasegawa, M. Fukuda, S. Nogami, K. Yabuuchi, Neutron irradiation effects on tungsten materials, Fusion Eng. Des. 89 (2014) 1568-1572. https://doi.org/10.1016/j.fusengdes.2014.04.035.

[20] T. Miyazawa, L.M. Garrison, J.W. Geringer, M. Fukuda, Y. Katoh, T. Hinoki, A. Hasegawa, Neutron irradiation effects on the mechanical properties of powder metallurgical processed tungsten alloys, J. Nucl. Mater. 529 (2020) 151910. https://doi.org/10.1016/j.jnucmat.2019.151910.

[21] N. Castin, A. Dubinko, G. Bonny, A. Bakaev, J. Likonen, A. De Backer, A.E. Sand, K. Heinola, D. Terentyev, The influence of carbon impurities on the formation of loops in tungsten irradiated with self-ions, J. Nucl. Mater. 527 (2019) 151808. https://doi.org/10.1016/j.jnucmat.2019.151808.

[22] L. Sun, S. Jin, X.-C. Li, Y. Zhang, G.-H. Lu, Hydrogen behaviors in molybdenum and tungsten and a generic vacancy trapping mechanism for $\mathrm{H}$ bubble formation, J. Nucl. Mater. 434 (2013) 395401. https://doi.org/10.1016/j.jnucmat.2012.12.008.

[23] Y.-L. Liu, H.-B. Zhou, Y. Zhang, G.-H. Lu, G.-N. Luo, Interaction of C with vacancy in W: A firstprinciples study, Comput. Mater. Sci. 50 (2011) 3213-3217. https://doi.org/10.1016/j.commatsci.2011.06.003. 
[24] Y.-W. You, X.-S. Kong, X.-B. Wu, C.S. Liu, Q.F. Fang, J.L. Chen, G.-N. Luo, Interaction of carbon, nitrogen and oxygen with vacancies and solutes in tungsten, RSC Adv. 5 (2015) 23261-23270. https://doi.org/10.1039/C4RA13854F.

[25] A. Alkhamees, H.-B. Zhou, Y.-L. Liu, S. Jin, Y. Zhang, G.-H. Lu, Vacancy trapping behaviors of oxygen in tungsten: A first-principles study, J. Nucl. Mater. 437 (2013) 6-10. https://doi.org/10.1016/j.jnucmat.2013.01.317.

[26] G.-H. Lu, H.-B. Zhou, C.S. Becquart, A review of modelling and simulation of hydrogen behaviour in tungsten at different scales, Nucl. Fusion. 54 (2014) 086001. https://doi.org/10.1088/0029-5515/54/8/086001.

[27] K. Heinola, T. Ahlgren, Diffusion of hydrogen in bcc tungsten studied with first principle calculations, J. Appl. Phys. 107 (2010) 113531. https://doi.org/10.1063/1.3386515.

[28] L. Yang, Z. j. Bergstrom, B. d. Wirth, Effect of interatomic potential on the energetics of hydrogen and helium-vacancy complexes in bulk, or near surfaces of tungsten, J. Nucl. Mater. (n.d.). https://doi.org/S0022311518310766.

[29] X.-S. Kong, Y.-W. You, C. Song, Q.F. Fang, J.-L. Chen, G.-N. Luo, C.S. Liu, First principles study of foreign interstitial atom (carbon, nitrogen) interactions with intrinsic defects in tungsten, J. Nucl. Mater. 430 (2012) 270-278. https://doi.org/10.1016/j.jnucmat.2012.07.008.

[30] Y.-L. Liu, H.-B. Zhou, S. Jin, Y. Zhang, G.-H. Lu, Dissolution and diffusion properties of carbon in tungsten, J. Phys. Condens. Matter. 22 (2010) 445504. https://doi.org/10.1088/0953$8984 / 22 / 44 / 445504$.

[31] C.S. Becquart, C. Domain, Ab initio calculations about intrinsic point defects and $\mathrm{He}$ in W, Nucl. Instrum. Methods Phys. Res. Sect. B Beam Interact. Mater. At. 255 (2007) 23-26. https://doi.org/10.1016/j.nimb.2006.11.006.

[32] A. Vehanen, P. Hautojärvi, J. Johansson, J. Yli-Kauppila, P. Moser, Vacancies and carbon impurities in $\alpha$ - iron: Electron irradiation, Phys. Rev. B. 25 (1982) 762-780. https://doi.org/10.1103/PhysRevB.25.762.

[33] A. Gentils, C. Cabet, Investigating radiation damage in nuclear energy materials using JANNuS multiple ion beams, Nucl. Instrum. Methods Phys. Res. Sect. B Beam Interact. Mater. At. 447 (2019) 107-112. https://doi.org/10.1016/j.nimb.2019.03.039.

[34] S.L. Dudarev, DPA definition and estimates, (n.d.) 10.

[35] R.E. Stoller, M.B. Toloczko, G.S. Was, A.G. Certain, S. Dwaraknath, F.A. Garner, On the use of SRIM for computing radiation damage exposure, Nucl. Instrum. Methods Phys. Res. Sect. B Beam Interact. Mater. At. 310 (2013) 75-80. https://doi.org/10.1016/j.nimb.2013.05.008.

[36] E. Soininen, J. Mäkinen, D. Beyer, P. Hautojärvi, High-temperature positron diffusion in Si, GaAs, and Ge, Phys. Rev. B. 46 (1992) 13104-13118. https://doi.org/10.1103/PhysRevB.46.13104.

[37] P. Desgardin, L. Liszkay, M.F. Barthe, L. Henry, J. Briaud, M. Saillard, L. Lepolotec, C. Corbel, G. Blondiaux, A. Colder, P. Marie, M. Levalois, Slow Positron Beam Facility in Orléans, Mater. Sci. Forum. 363-365 (2001) 523-525. https://doi.org/10.4028/www.scientific.net/MSF.363-365.523. 
[38] A. Debelle, M.F. Barthe, T. Sauvage, First temperature stage evolution of irradiation-induced defects in tungsten studied by positron annihilation spectroscopy, J. Nucl. Mater. 376 (2008) 216221. https://doi.org/10.1016/j.jnucmat.2008.03.002.

[39] M. Sidibe, Etude du comportement du tungstène sous irradiation : applications aux réacteurs de fusion, phdthesis, Université d'Orléans, 2014. https://tel.archives-ouvertes.fr/tel-01068634 (accessed January 7,2021 ).

[40] T. Troev, E. Popov, P. Staikov, N. Nankov, T. Yoshiie, Positron simulations of defects in tungsten containing hydrogen and helium, Nucl. Instrum. Methods Phys. Res. Sect. B Beam Interact. Mater. At. 267 (2009) 535-541. https://doi.org/10.1016/j.nimb.2008.11.045.

[41] J. Fikar, R. Schäublin, Stability of small vacancy clusters in tungsten by molecular dynamics, Nucl. Instrum. Methods Phys. Res. Sect. B Beam Interact. Mater. At. (n.d.). https://doi.org/10.1016/j.nimb.2019.11.044.

[42] A. van Veen, H. Schut, J. de Vries, R.A. Hakvoort, M.R. Ijpma, Analysis of positron profiling data by means of “"VEPFIT,"' in: AIP Conf. Proc., AIP, Ontario (Canada), 1991: pp. 171-198. https://doi.org/10.1063/1.40182.

[43] A. Vehanen, K.G. Lynn, P.J. Schultz, E. Cartier, H.-J. Güntherodt, D.M. Parkin, Variable-energy positron studies of metallic glasses, Phys. Rev. B. 29 (1984) 2371-2381. https://doi.org/10.1103/PhysRevB.29.2371.

[44] P.J. Schultz, K.G. Lynn, Interaction of positron beams with surfaces, thin films, and interfaces, Rev. Mod. Phys. 60 (1988) 701-779. https://doi.org/10.1103/RevModPhys.60.701.

[45] Q. Xu, T. Yoshiie, H.C. Huang, Molecular dynamics simulation of vacancy diffusion in tungsten induced by irradiation, Nucl. Instrum. Methods Phys. Res. Sect. B Beam Interact. Mater. At. 206 (2003) 123-126. https://doi.org/10.1016/S0168-583X(03)00697-9.

[46] Hautoj\&auml;rvi P., Corbel C., Positron Spectroscopy of Defects in Metals and Semiconductors, Proc. Int. Sch. Phys. LdquoEnrico Fermirdquo. 125 (1995) 491-532. https://doi.org/10.3254/978-1-61499-211-0-491.

[47] B. Yao, D.J. Edwards, R.J. Kurtz, G.R. Odette, T. Yamamoto, Multislice simulation of transmission electron microscopy imaging of helium bubbles in Fe, J. Electron Microsc. (Tokyo). 61 (2012) 393-400. https://doi.org/10.1093/jmicro/dfs065.

[48] A.V. Michel, G. Carlot, C. Onofri, C. Sabathier, M. Cabié, M. Dumont, TEM characterisation of helium platelets in implanted uranium dioxide, J. Nucl. Mater. 528 (2020) 151832. https://doi.org/10.1016/j.jnucmat.2019.151832.

[49] P.-E. Lhuillier, Etude du comportement de l'hélium et des défauts lacunaires dans le tungstène, phdthesis, Université d'Orléans, 2010. https://tel.archives-ouvertes.fr/tel-00587482 (accessed January 7, 2021).

[50] A. Vehanen, K.G. Lynn, P.J. Schultz, M. Eldrup, Improved slow-positron yield using a single crystal tungsten moderator, Appl. Phys. A. 32 (1983) 163-167. https://doi.org/10.1007/BF00616613.

[51] A. De Backer, P.E. Lhuillier, C.S. Becquart, M.F. Barthe, Modelling of the implantation and the annealing stages of $800 \mathrm{keV} 3 \mathrm{He}$ implanted tungsten: Formation of nanovoids in the near surface region, J. Nucl. Mater. 429 (2012) 78-91. https://doi.org/10.1016/j.jnucmat.2012.05.024. 
606 [52] P. Asoka-Kumar, J.H. Hartley, R.H. Howell, P.A. Sterne, D. Akers, V. Shah, A. Denison, Direct observation of carbon-decorated defects in fatigued type 304 stainless steel using positron annihilation spectroscopy, Acta Mater. 50 (2002) 1761-1770. https://doi.org/10.1016/S1359-

$6096454(02) 00027-7$.

610 [53] R. Rementeria, R. Domínguez-Reyes, C. Capdevila, C. Garcia-Mateo, F.G. Caballero, Positron 611 Annihilation Spectroscopy Study of Carbon-Vacancy Interaction in Low-Temperature Bainite, Sci. Rep. 61210 (2020) 487. https://doi.org/10.1038/s41598-020-57469-x.

613 